\title{
Impacts of Crop Variety and Time of Inoculation on the Susceptibility and Tolerance of Winter Wheat to Wheat streak mosaic virus
}

Z. Miller and F. Menalled, Department of Land Resources and Environmental Sciences, and D. Ito, former graduate student, M. Moffet, and M. Burrows, Department of Plant Sciences and Plant Pathology, Montana State University, Bozeman 59717

\begin{abstract}
Miller, Z., Menalled, F., Ito, D., Moffet, M., and Burrows, M. 2014. Impacts of crop variety and time of inoculation on the susceptibility and tolerance of winter wheat to Wheat streak mosaic virus. Plant Dis. 98:1060-1065.

Plant genotype, age, size, and environmental factors can modify susceptibility and tolerance to disease. Understanding the individual and combined impacts of these factors is needed to define improved disease management strategies. In the case of Wheat streak mosaic virus (WSMV) in winter wheat, yield losses and plant susceptibility have been found to be greatest when the crop is exposed to the virus in the fall in the central and southern Great Plains. However, the seasonal dynamics of disease risk may be different in the northern Great Plains, a region characterized by a relatively cooler fall conditions, because temperature is known to modify plant-virus interactions. In a 2-year field study conducted in south-central Montana, we compared the impact of fall and spring WSMV inoculations on the susceptibility,

tolerance, yield, and grain quality of 10 winter wheat varieties. Contrary to previous studies, resistance and yields were lower in the spring than in the fall inoculation. In all, 5 to $7 \%$ of fall-inoculated wheat plants were infected with WSMV and yields were often similar to uninoculated controls. Spring inoculation resulted in 45 to $57 \%$ infection and yields that were 15 to $32 \%$ lower than controls. Although all varieties were similarly susceptible to WSMV, variations in tolerance (i.e., yield losses following exposure to the virus) were observed. These results support observations that disease risk and impacts differ across the Great Plains. Possible mechanisms include variation in climate and in the genetic composition of winter wheat and WSMV across the region.
\end{abstract}

Wheat streak mosaic virus (WSMV) causes significant disease and yield losses in all major wheat production regions around the globe (20). In the Great Plains region of the United States, WSMV is the most common virus in both spring and winter wheat (3), where it reduces crop yields by approximately 5\% per year (6). WSMV is transmitted by the wheat curl mite (WCM; Aceria tosichella Keifer; 29). The virus and its vector require living plant hosts for survival and reproduction and can infest a diverse set of cereal crop and grassy weed species (20).

The efficacy of conventional disease control measures has been limited for this disease complex. Genes providing resistance to WSMV have not been widely incorporated into regionally adapted cultivars and utility of these resistance genes is limited due to temperature sensitivity $(9,24,25)$. Resistance to the WCM has also been deployed (4); however, vectors evolve rapidly to overcome resistance (10). No currently registered pesticides provide effective or economically viable control of the vector $(11,33)$.

Assessment of disease risk and management practices that minimize these risks is largely based upon knowledge of the seasonal dynamics of WSMV exposure and impacts of that exposure in the crop (35). WSMV exposure can occur throughout the growing season. In winter wheat, exposure to virus and vectors is greatest in the late summer to early fall, as the current years' cereal crops are maturing $(30,36)$. Exposure can also occur in the spring, as shown by the fact that WSMV is also common in spring wheat $(8 ; \mathrm{M}$. Burrows, personal communication). Spring exposure (i.e., movement of vectors to healthy wheat) can occur due to increasing mite populations (32) and herbicide-induced death of infested grassy weeds and volunteer crops $(2,14)$. The effects of disease exposure and management tactics, such as crop variety selection, on disease impacts are largely determined by their effects on the

Corresponding author: M. Burrows, E-mail: mburrows@montana.edu

Accepted for publication 23 February 2014.

http://dx.doi.org/10.1094/PDIS-12-13-1210-RE

(c) 2014 The American Phytopathological Society likelihood that the crop gets infected if exposed to the virus (i.e., susceptibility) and the impacts of exposure on yield and grain quality (i.e., tolerance).

Plant susceptibility and tolerance to infection can be affected by plant genotype, age, size, or correlated environmental factors. Evidence suggests that, similar to other cereal viruses $(5,21)$, wheat resistance and tolerance to WSMV increase with plant age (i.e., growth stage). In a greenhouse experiment, symptoms and damage were severe when wheat was inoculated prior to tillering but were less frequent and relatively mild when wheat was inoculated later (28). In winter wheat grown in the central and southern Great Plains, impacts of fall exposure are severe whereas the effects of spring exposure are relatively mild (12,27). In Kansas, Somsen and Sill (31) observed that winter wheat can become infected in the spring but not after plant jointing, when plant resistance develops. Similarly, Wegulo and colleagues (35) stated that, in Nebraska, winter wheat plants infected during the fall exhibit increased severity of disease and increased yield losses compared with infection in the spring, where symptoms and yield impacts may be subtle or nonexistent. Accordingly, a field study conducted in Oklahoma (12) observed that, across six winter wheat varieties and 2 years, yield reductions due to spring inoculation with WSMV were significant in one-half of the variety-years and ranged from 3 to $23 \%$ less than uninoculated controls. In contrast, fall inoculation resulted in significant yield reductions in all varieties and years, ranging from 70 to $84 \%$.

Timing of infection may have different effects in the northern versus the southern Great Plains because viral replication and the expression of genes that confer resistance to WSMV are temperature dependent $(24,25)$, and plant-virus interactions are often temperature dependent (15). Understanding how the relationship between timing of infection and crop susceptibility and tolerance varies across the Great Plains is critical to designing regionally appropriate disease management practices such as optimal planting dates and screening for crop resistance or tolerance.

The objective of this study was to determine the effects of plant genotype, crop age, and associated environmental factors that are correlated with crop age on susceptibility and tolerance of winter wheat to WSMV infection in the northern Great Plains. Specifi- 
cally, we tested, first, whether winter wheat inoculated with WSMV in the fall is more susceptible to infection and yield loss relative to spring inoculation. Second, we assessed the extent to which winter wheat varieties differ in their resistance and tolerance to WSMV inoculation and whether the varietal differences vary based on when they were exposed to WSMV. Resistance and tolerance often vary among wheat varieties $(1,12,18)$. However, regionally relevant comparisons of modern winter wheat varieties had not been performed in Montana. The effects of these treatments on grain quality measures (protein content, test weights, and kernel weights) were also tested. Protein content and test weights are used to grade wheat quality and affect grain prices received by producers.

\section{Materials and Methods}

Experimental design. Field experiments were conducted from 2007 to 2009 at the Arthur H. Post Research Farm, four miles west of Bozeman, MT. The soil is an Amsterdam-Quagle silt loam, $\mathrm{pH}$ 7.5. Studies were designed as a randomized complete block with four repetitions, with winter wheat variety as the main plot treatment. Inoculation treatments (controls, fall-inoculated, and springinoculated) were applied to rows (split plots) within the main plots. Each main plot consisted of five rows of wheat. Rows were $6.0 \mathrm{~m}$ long, with $0.3 \mathrm{~m}$ between rows. The controls consisted of noninoculated wheat in 2007-08 and 2008-09. In the 2008-09 season, a buffer treatment was included that did not differ from the noninoculated control. Inoculation treatments were applied in the same spatial pattern within each plot to minimize errors in application. Ten winter wheat varieties ('Genou', 'Jagalene', 'MTV0734', 'Morgan', 'Neeley', 'Pryor', 'Rampart', 'Rocky', 'Tiber', and 'Yellowstone') were chosen based on acreage in the state (U.S. Department of Agriculture National Agricultural Statistics Service) and consultations with crop breeders in Montana. All varieties are commercially available except an experimental line of winter wheat, MTV0734.

Plots were fallow the previous growing season and maintained according to standard agronomic practices. Planting dates for winter wheat were 8 October 2007 and 24 September 2008. Plots were planted at the rate of 60 seeds $/ \mathrm{m}^{2}$. Plots were fertilized with nitrogen at a rate of $292 \mathrm{~kg} \mathrm{ha}^{-1}$. Starter fertilizer (5-26-25) was applied at planting at a rate of $112 \mathrm{~kg} \mathrm{ha}^{-1}$. The remaining $286 \mathrm{~kg} \mathrm{ha}^{-1}$ of the nitrogen was applied as top-dressed urea in the spring. Weeds were removed by an application of pyrsulfotole $\left(41 \mathrm{~g}\right.$ a.i. $\left.\mathrm{ha}^{-1}\right)$ and bromoxynil (230 g a.i. $\left.\mathrm{ha}^{-1}\right)$ at tillering.

Virus inoculation. A WSMV isolate from Conrad, MT (Conrad I) was used as the standard isolate for this studies (13). Isolate stocks were maintained at $-80^{\circ} \mathrm{C}$ until use. Sequence analysis of the coat protein within isolate Conrad 1 (accession HM535796.2) using forward primer $\mathrm{H} 8369$ and reverse primer C8908 (19) showed a $>99 \%$ sequence identity to WSMV Sidney 81 (GenBank accession AF057533.1).

To prepare inoculum, spring wheat 'Choteau' was inoculated by hand rubbing isolate stocks diluted 1:10 (wt/vol) in phosphatebuffered saline (PBS; pH 7.2) with $1 \%$ carborundum. Plants were maintained as described by Ito et al. (13). Two weeks after inoculation, these stock plants were used to inoculate flats ( 35 by 50 $\mathrm{cm}$ ) of spring wheat at growth stage Feekes 2. Plants were inoculated with a high-pressure Husky siphon feed spray gun (Home Depot, Inc.) powered by an air compressor (CompAir) to deliver the inoculum with $0.05 \%$ carborundum from a height of 5 $\mathrm{cm}$ from the top of plant at a rate of approximately $20 \mathrm{ml}$ of inoculum per $30 \mathrm{~cm}^{2}$ at 80 PSI. No vectors or virus spread to healthy check plants were noted during the experiment.

Approximately 21 days after inoculation, plant tissue was collected and transported to the field on ice. Leaves were roughly chopped, then thoroughly blended 1:10 (wt/vol) with PBS. Carborundum was added at $0.5 \%(\mathrm{wt} / \mathrm{vol})$ and agitated during inoculation. Winter wheat plants were mechanically inoculated in the field with infectious sap produced within $1 \mathrm{~h}$ of blending. Fall inoculation in 2007 was performed via rubbing by hand. All other inocula- tions were done by spraying rows with a custom wood jig designed to hold a paint sprayer at an approximately $15^{\circ}$ forward angle and $5 \mathrm{~cm}$ above the plant canopy, and allowing control from an upright position while walking at approximately 35 to $40 \mathrm{steps} / \mathrm{min}$. Pressure for the inoculation was provided by an air compressor at 80 PSI. In the first trial, fall inoculation of winter wheat occurred on 29 October 2007 and spring inoculation on 16 May 2008. In the second trial, inoculation occurred on 10 October 2008 and 18 May 2009. Fall inoculation was applied at Feekes growth stage 1 to 2 . Spring inoculation was applied at Feekes growth stage 3 to 4. Crop densities did not differ between fall and spring inoculations.

Virus incidence. In all, 20 and 30 flag leaves were randomly sampled from the center $1.0 \mathrm{~m}$ of each row on 18 June 2008 and 22 June 2009, respectively. All leaves were processed individually with enzyme-linked immunosorbent assay (ELISA), as described by Ito et al. (13). The absorbance (optical density) values of the negative controls (healthy wheat) were used to identify infected plants. The mean and standard deviation of six negative controls of each cultivar on each plate were calculated and used to set a probabilistic optical density threshold at three standard deviations above the mean, beyond which plants were considered infected.

Agronomic variables. All plots were harvested on 12 August 2008 and 27 August 2009. Single rows were cut with a Suzue harvest-binder (EN25L-2; Suzue Manufacturing). Yield samples were collected from a 3-m section at the center of each row. Wheat bundles were allowed to dry for 1 to 2 days before thrashing with a Vogel thrasher (custom built by Bill's Welding). Yield was adjusted to $13 \%$ moisture. Grain quality measures (protein concentration, test weight, and thousand-kernel weight [TKW]) were collected by the Montana State University Cereal Quality Laboratory according to standard procedures. TKW data were only collected in 2008.

Weather data. Weather data was collected by a weather station located at the study site (Bozeman AGRIMET).

Statistical analysis. A split plot analysis of variance was used to assess differences in WSMV incidence, and wheat yield and grain quality measures across wheat varieties and time of inoculation. In this model, varieties were modeled as a fixed effect at the mainplot level and the effects of inoculation treatments were tested at the split-plot level. Trial (study-year) was included as a fixed effect to test for consistency of results between years. Incidence data was logit transformed and analyzed as the natural $\log$ of the odds of infection (34). Residuals for experimental data were examined for assumption of normality with the Shapiro-Wilk's test (26) and homogeneity of variances by the Levene's test (17). Grain protein and test weight responses were analyzed individually by year due to significant differences in the residual variation between trials. Data were log transformed as necessary, although untransformed data are presented in the results. The $t$ tests based on the residual error were used to test for differences between inoculation treatments within each variety. Differences among varieties were compared using Tukey's honestly significant difference. All statistical analyzes were conducted in R (R-Core Development Team).

\section{Results}

Temperatures and precipitation during the study period were similar to the long-term average (LTA) for the site. These environmental variables were also similar between the 2 years of this study (Figs. 1 and 2). A severe hail storm occurred on 22 July 2008. The hail damaged crop stands, resulting in reduced yields in 2008 compared with 2009 harvests. Mean yields in the control plots in 2008 were $3.1 \mathrm{t} / \mathrm{ha}, 50 \%$ less than the average yields in 2009 (mean = $6.2 \mathrm{t} / \mathrm{ha}$ ). Hail damage may have altered effects of wheat varieties and inoculation treatments or decreased power to detect treatment effects.

Susceptibility to WSMV was similar among varieties and trials $(P>0.1$, Table 1$)$. Timing of inoculation largely determined infection rates, explaining over $85 \%$ of the variation observed at the split-plot level (inoculation $F_{1,70}=483, P<0.001$ ). Fall-inoculated winter wheat had a 10-fold lower incidence of WSMV (mean = $5.8 \%, 95 \%$ confidence interval $[\mathrm{CI}] 4.4$ to $7.4 \%$ ) than spring- 
inoculated winter wheat $($ mean $=55.1 \%, 95 \%$ CI 48.2 to $61.7 \%)$ (Table 1).

The effects of timing of inoculation on yields were generally correlated with the effects of incidence. Averaged across both trials and varieties, exposure to WSMV in the fall, where infection rates were low, did not reduce yields, whereas spring exposure did (inoculation $\left.F_{2,120}=73.4, P<0.001\right)$. However, the effects of inoculation treatments on yields varied among crop varieties (varietyinoculation $F_{18,120}=3.3, P<0.001$ ) and between trials (year-inoculation $\left.F_{2,120}=4.5, P<0.001\right)$ but showed no dependence among these three factors (variety-inoculation-trial $F_{18,120}=1.5, P>0.1$ ). The interaction between study year and inoculation was driven by variation in the effects of fall inoculation on yields. In 2008, fall inoculation reduced yields by $14.6 \%(95 \% \mathrm{CI}=9.9$ to 19.0$)$ but did not affect yields in 2009. Effects of spring inoculation ranged from $23.0 \%$ (95\% CI $=18.8$ to 27.0 ) less than controls in 2008 to an $18.1 \%(95 \% \mathrm{CI}=13.6$ to 22.3$)$ reduction in 2009 .

The effects of WSMV inoculation treatments on yield differed among varieties (variety-inoculation $F_{18,120}=3.3, P<0.001$ ). Of the tested varieties, Pryor was consistently among the highestyielding lines and exhibited the greatest tolerance to WSMV inoculation. WSMV inoculation had no effects on yields for Pryor. In both fall- and spring-inoculated treatments, Pryor out-yielded five and seven varieties, respectively (Table 2). Tolerance (i.e., proportional effects of WSMV inoculation on yield) in Rampart, Jagalene, and Rocky were similar to Pryor in both fall and spring inoc-

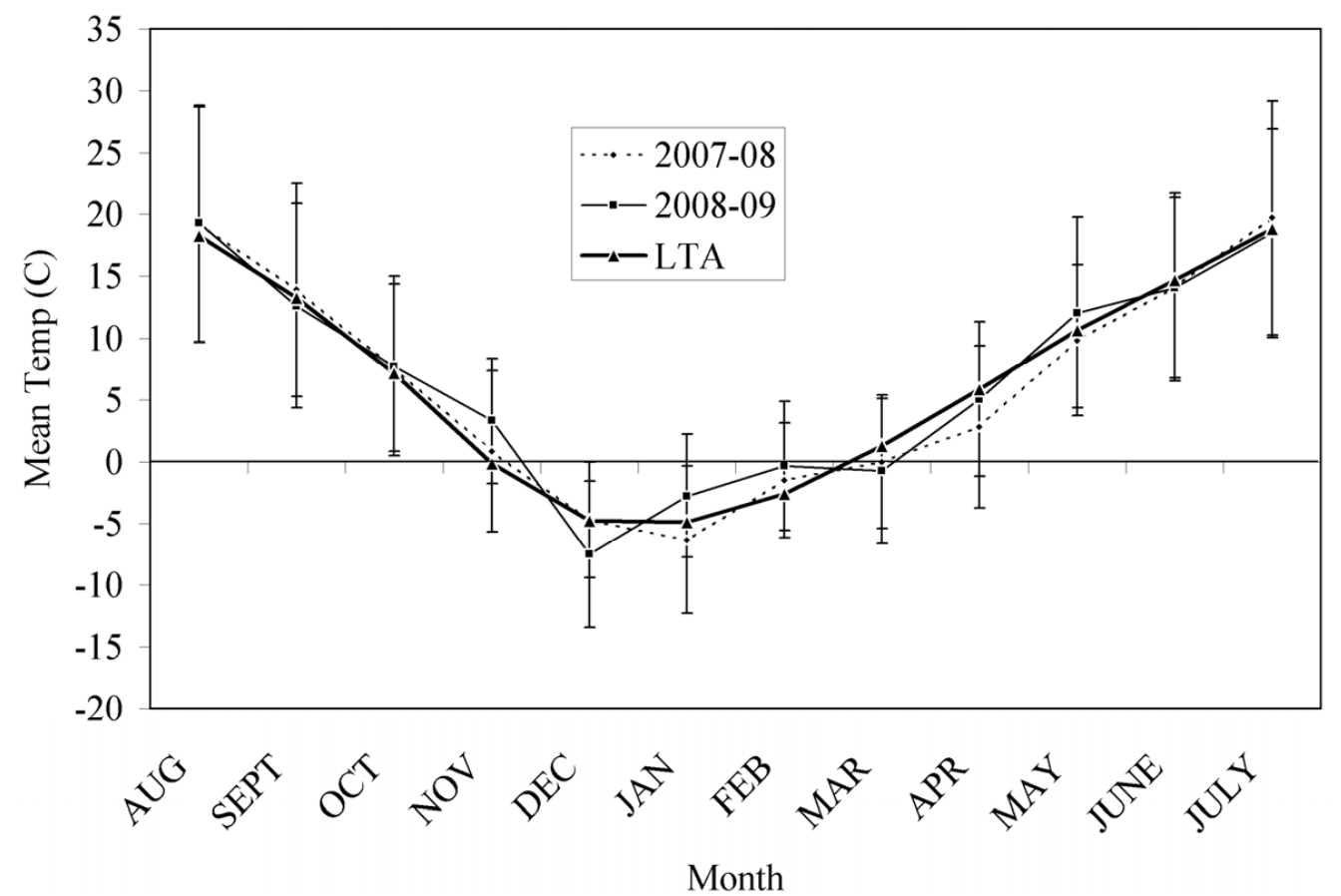

Fig. 1. Mean temperatures $\left({ }^{\circ} \mathrm{C}\right)$ during the study years. Long-term average (LTA) is based on 45 years of data (1966-2011). Error bars depict mean minimum and maximum temperatures for each month.

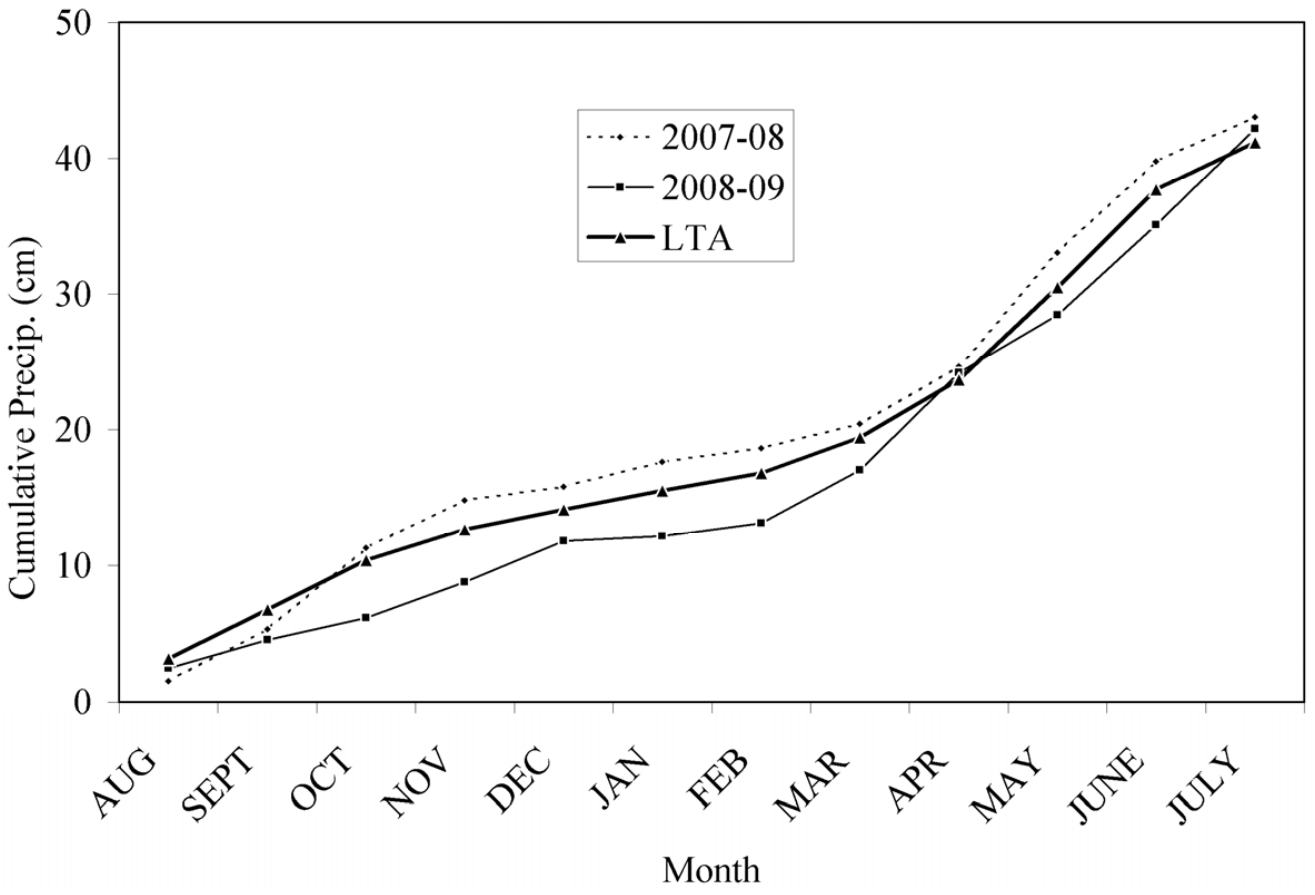

Fig. 2. Cumulative precipitation (in centimeters) during the study years. Long-term average (LTA) is based on 45 years of data (1966-2011). 
ulations. A subset of varieties was relatively sensitive to WSMV, including Morgan, MTV0734, Neeley, and Tiber (Table 2).

Protein levels were affected by both variety and inoculation time (Table 3). Protein content differed among varieties $\left(2008 F_{9,27}=\right.$ 4.4, $P<0.005 ; 2009 F_{9,27}=30.9, P<0.001$; Table 3). Grain protein was increased by inoculation $\left(2008 F_{2,60}=22.3, P<0.001\right.$; $2009 F_{2,60}=16.2, P<0.001$; Table 3) and effects were almost exclusively associated with spring inoculation (Table 3). In 2008, the effects of inoculation treatments differed among varieties $\left(F_{2,60}\right.$ $=2.3, P<0.05)$. Fall inoculation increased protein content in one variety, while spring inoculation resulted in increases in four varieties. In 2009, spring inoculation increased protein content similarly across varieties. The increase in protein levels associated with fall inoculation relative to the controls was driven by two significant outliers (high protein values in the fall inoculation treatment). When they are removed from the data set, mean protein content following fall inoculation was $13.5 \%$ and was similar to uninoculated controls.

Effects of WSMV on test weight were associated with spring inoculation $(P<0.001)$ but not with inoculation in the fall $(P>0.10)$ (Table 3). Spring inoculation reduced test weight by an average of $2.1 \mathrm{~kg} \mathrm{hl}^{-1}$ in all varieties except Genou, in 2009, where test weights were similar to controls. TKW differed among varieties

Table 1. Effect of Wheat streak mosaic virus (WSMV) timing of inoculation (Fall, Spring) on incidence of WSMV in winter wheat varieties

\begin{tabular}{|c|c|c|c|c|}
\hline \multirow[b]{3}{*}{ Variety } & \multicolumn{4}{|c|}{ Incidence of WSMV $(\%)^{y}$} \\
\hline & \multicolumn{2}{|c|}{2008} & \multicolumn{2}{|c|}{2009} \\
\hline & Fall & Spring & Fall & Spring \\
\hline Genou & 10.0 & 65.0 & 3.4 & 59.2 \\
\hline Jagalene & 12.5 & 75.0 & 6.7 & 58.3 \\
\hline MTV0734 & 6.3 & 38.8 & 9.2 & 48.3 \\
\hline Morgan & 2.5 & 73.8 & 12.5 & 66.7 \\
\hline Neeley & 6.3 & 55.0 & 7.5 & 60.0 \\
\hline Pryor & 10.0 & 38.8 & 2.5 & 54.2 \\
\hline Rampart & 6.3 & 43.8 & 10.2 & 64.2 \\
\hline Rocky & 3.8 & 50.0 & 5.0 & 46.7 \\
\hline Tiber & 16.3 & 37.5 & 2.5 & 63.3 \\
\hline Yellowstone & 7.5 & 55.0 & 4.2 & 42.1 \\
\hline $\operatorname{Mean}^{2}$ & 8.1 & 53.3 & 6.4 & 56.3 \\
\hline
\end{tabular}

${ }^{\mathrm{y}}$ Incidence of WSMV was measured using enzyme-linked immunosorbent assay at Feekes growth stage 9.

${ }^{2}$ Means of percent incidence. Note, means given in text were calculated from logit-transformed data. Differences in incidence between fall and spring inoculations were significant and did not differ between trial-years or varieties.
$\left(F_{9,27}=7.1, P<0.001 ;\right.$ results not shown $)$ and was reduced by inoculation $\left(F_{2,60}=12.6, P<0.001\right)$. Post-hoc tests indicated that fall inoculation $($ mean $=25.4 \mathrm{~g}$ ) did not alter TKW relative to the controls (mean $=25.3 \mathrm{~g}$ ) but spring inoculation decreased TKW by $0.9 \mathrm{~g}(95 \% \mathrm{CI}=0.5$ to 1.2$)$ to a mean of $24.7 \mathrm{~g}$.

\section{Discussion}

Understanding the individual and joint impacts of biological and environmental variables on plants' susceptibility and tolerance to pathogens is a required step to inform ecologically based disease management. In this context, assessing the relationship between timing of infection and disease impacts can provide critical information in the design of regionally appropriate management prac-

Table 2. Effects of fall and spring Wheat streak mosaic virus (WSMV) inoculation on yields among winter wheat varieties averaged over two trials conducted in 2007-08 and 2008-09

\begin{tabular}{lccc}
\hline & \multicolumn{3}{c}{ Mean yield $\left(\mathbf{t ~ h a}^{-1}\right)^{\mathbf{z}}$} \\
\cline { 2 - 4 } Variety & Control & Fall & Spring \\
\hline Yellowstone & $5.32 \mathrm{a}$ & $* 4.58 \mathrm{abc}$ & $* 4.47 \mathrm{ab}$ \\
& & $(-15) \mathrm{BCD}$ & $(-16) \mathrm{ABC}$ \\
Neeley & $5.25 \mathrm{a}$ & $\begin{array}{c}* .59 \mathrm{abc} \\
(-15) \mathrm{BCD}\end{array}$ & $\begin{array}{c}* 3.39 \mathrm{de} \\
(-38) \mathrm{E}\end{array}$ \\
Pryor & $5.15 \mathrm{a}$ & $5.33 \mathrm{a}$ & $4.84 \mathrm{a}$ \\
& & $-3 \mathrm{~A}$ & $(-1) \mathrm{A}$ \\
Genou & $4.79 \mathrm{ab}$ & $4.67 \mathrm{ab}$ & $* 3.92 \mathrm{bc}$ \\
& & $(-4) \mathrm{AB}$ & $(-20) \mathrm{BCD}$ \\
Rampart & $4.65 \mathrm{ab}$ & $4.35 \mathrm{abc}$ & $* 3.92 \mathrm{abc}$ \\
& & $(-8) \mathrm{ABCD}$ & $(-16) \mathrm{ABC}$ \\
MTV0734 & $4.52 \mathrm{ab}$ & $* 3.57 \mathrm{~cd}$ & $* 3.34 \mathrm{cde}$ \\
& & $(-23) \mathrm{D}$ & $(-28) \mathrm{CDE}$ \\
Morgan & $4.47 \mathrm{ab}$ & $4.27 \mathrm{bc}$ & $* 3.51 \mathrm{cde}$ \\
& & $(-3) \mathrm{AB}$ & $(-22) \mathrm{BCD}$ \\
Tiber & $4.41 \mathrm{ab}$ & $* 3.76 \mathrm{~d}$ & $* 3.27 \mathrm{de}$ \\
& & $(-21) \mathrm{CD}$ & $(-31) \mathrm{DE}$ \\
Jagalene & $4 \mathrm{bc}$ & $4 \mathrm{bcd}$ & $* 3.47 \mathrm{~cd}$ \\
& & $0 \mathrm{AB}$ & $(-11) \mathrm{AB}$ \\
Rocky & $3.54 \mathrm{c}$ & $3.42 \mathrm{~d}$ & $* 3.06 \mathrm{e}$ \\
& & $(-5) \mathrm{ABC}$ & $(-16) \mathrm{ABCD}$ \\
\hline
\end{tabular}

${ }^{\mathrm{z}}$ Numbers in parentheses indicate the percentage yield loss relative to control $\left[100 \% \times\left(\right.\right.$ yield $_{\text {inoculated }} /$ yield $\left.\left._{\text {control }}-1\right)\right]$ for each inoculation and varietal treatment. Significant reductions in yield compared with the control are indicated with an asterisk (*). Within each inoculation treatment, means followed by a different letter differed in Tukey's honestly significant difference post-hoc tests. Mean yields and percentage yield losses (effects of inoculation) are compared separately. Groups are noted in lowercase letters for mean yields and uppercase for WSMV effects on yield.

Table 3. Effects of Wheat streak mosaic virus (WSMV) inoculation in fall and spring on grain protein content (\%) in 10 winter wheat varieties in 2008 and $2009^{\mathrm{w}}$

\begin{tabular}{|c|c|c|c|c|c|c|c|}
\hline \multirow[b]{2}{*}{ Variety } & \multicolumn{3}{|c|}{$2008^{x}$} & \multicolumn{4}{|c|}{$2009^{y}$} \\
\hline & Control & Fall & Spring & Control & Fall & Spring & Mean 2009 \\
\hline Rampart & $15.1 \mathrm{a}$ & $15.2 \mathrm{a}$ & $15.4 \mathrm{a}$ & 14.6 & 14.7 & 14.6 & $14.6 \mathrm{a}$ \\
\hline Neeley & $14.5 \mathrm{ab}$ & $14.3 \mathrm{~b}$ & $14.6 \mathrm{ab}$ & 12.7 & 12.8 & 13.4 & $13.0 \mathrm{cde}$ \\
\hline Tiber & $14.0 \mathrm{bc}$ & $14.2 \mathrm{~b}$ & $* 14.8 \mathrm{a}$ & 13.8 & 13.8 & 13.7 & $13.7 \mathrm{abcd}$ \\
\hline Genou & $13.7 \mathrm{~cd}$ & $13.7 \mathrm{bc}$ & $14.1 \mathrm{bc}$ & 14.0 & 14.0 & 14.0 & $14.0 \mathrm{abc}$ \\
\hline Yellowstone & $13.2 \mathrm{de}$ & $12.9 \mathrm{~d}$ & $13.0 \mathrm{de}$ & 12.3 & 12.5 & 12.8 & $12.5 \mathrm{de}$ \\
\hline Jagalene & $13.1 \mathrm{de}$ & $12.8 \mathrm{~d}$ & $13.3 \mathrm{de}$ & 13.9 & 14.0 & 14.2 & $14.0 \mathrm{abc}$ \\
\hline Pryor & $13.0 \mathrm{de}$ & $12.6 \mathrm{~d}$ & $12.8 \mathrm{e}$ & 12.0 & 12.5 & 12.6 & $12.4 \mathrm{e}$ \\
\hline Morgan & $12.8 \mathrm{e}$ & $12.8 \mathrm{~d}$ & $* 13.3 \mathrm{de}$ & 13.3 & 13.4 & 13.5 & 13.4 bcde \\
\hline MTV0734 & $12.7 \mathrm{e}$ & $* 13.2 \mathrm{~cd}$ & $* 13.6 \mathrm{~cd}$ & 14.1 & 14.3 & 14.4 & $14.3 \mathrm{ab}$ \\
\hline Rocky & $12.5 \mathrm{e}$ & $12.8 \mathrm{~d}$ & $* 13.6 \mathrm{~cd}$ & 13.6 & 13.9 & 14.0 & $13.8 \mathrm{abc}$ \\
\hline Mean & 13.4 & 13.5 & 13.9 & $13.4 \mathrm{~b}$ & $13.6 \mathrm{a}^{\mathrm{z}}$ & $13.7 \mathrm{a}$ & $\ldots$ \\
\hline
\end{tabular}

${ }^{\mathrm{w}}$ Treatment means followed different letters were significantly different in post-hoc tests. Asterisks denote significant effects of WSMV inoculation relative to the controls.

${ }^{\mathrm{x}}$ Effect of inoculation treatment varied among varieties. Post-hoc comparisons were done within variety and inoculation treatments.

${ }^{y}$ Effects of inoculation and variety treatments were independent. Post-hoc comparisons were done separately among varieties and among inoculation treatments.

${ }^{\mathrm{z}}$ The effect of spring inoculation is driven by significant outliers in Pryor and Yellowstone. When these outliers are removed, the mean protein content is not significant from the controls. 
tices. Contrary to previous results $(12,28,31)$, this study indicated that, in winter wheat, fall inoculation with WSMV does not necessarily result in higher infection rates or yield impacts when compared with spring inoculation. Instead, spring inoculation was associated with an up to 10-fold increase in infection rates, and was more likely to affect yields and grain quality than fall inoculation.

These regional differences provide insights into the mechanisms driving the dynamics of WSMV in cereal crops. Our results expand previous observations from the southern Great Plains of the importance of environmental conditions and plant size in determining winter wheat responses to WSMV. Differences in the effects of time of exposure to WSMV across the Great Plains could be due to dissimilar climate and genotypes of hosts and viruses across the region. Although this study does not allow us to determine the extent to which environmental and biological factors were responsible for the observed differences between the northern and southern Great Plains, it is likely that climate played a significant role. First, the regional differences in resistance and impacts of WSMV occur in the fall, when climate differences are most pronounced across the Great Plains. In the southern Great Plains, yield reductions due to fall inoculation resulted in 70 to $84 \%$ yield reductions (12). In our study, fall inoculation reduced yields in less than half of the varieties and, in these varieties, yield decreases were relatively small, ranging between 15 and $23 \%$. The effects of spring inoculation appear to be relatively consistent across the region. Hunger et al. (12) observed that spring inoculation with WSMV lowered yields in one-half of the variety-years, with values ranging from 3 to $23 \%$. In our study, spring inoculation reduced yield in $90 \%$ of varieties and yield reductions ranged from 1 to $38 \%$.

The regional differences in the effects of fall exposure to WSMV on yields are likely driven differences in crop resistance (i.e., incidence). In this study, fall inoculation resulted in low incidence and, consequently, little or no yield reductions. The variation in crop resistance in the fall across the Great Plains appears to be linked to climate but the mechanism for this pattern is unknown. In this study, WSMV incidence was measured in the spring and reflects the probability of systemic infection. Consequently, the lower incidence of WSMV following fall inoculation could be due to reduced likelihood of infection (resistance) or reduced rates of systemic infection. Resistance genes are known to be more effective at lower temperatures $(9,16,24,25)$ but our results suggest that plant resistance in the absence of resistance genes may also increase as temperatures decline. In addition to cooler temperatures increasing resistance, the lower infection rates seen in the fall inoculation treatments could be due to increased rates of loss of infection over the winter. Research is needed to determine the effects of near- and below-freezing temperatures on the infection and viral movement of WSMV in winter wheat.

Further research is also needed to validate the assumption that mechanical inoculation provides accurate estimates of the effects of time of WSMV exposure on disease risk in the field where WSMV is transmitted by WCMs. This and previous studies $(1,8,12,16)$ assessed winter wheat disease tolerance and susceptibility through mechanical inoculation. Yet, evidence suggests that plant susceptibility to WSMV exposure differs between these inoculation methods $(13,29)$. To validate the results presented here, similar experiments should be conducted using WCMs to inoculate the crop. Without such experiments, it is difficult to extrapolate these results to production fields.

It is important to note that our results do not suggest that WSMV risk is low throughout the entire fall in the northern Great Plains or that fall exposure does not pose a threat to winter wheat production. The rate of vector immigration peaks in September, when grain crops are maturing and mites leave their hosts (Z. Miller and M. Burrows, unpublished data), and winter wheat that has emerged by this time will likely be exposed to the virus. Exposure to WSMV during this early fall period, when temperatures may be relatively high, will likely result in high infection rates and impacts on wheat yields. These infections in early-emerging winter wheat would also contribute to increased year-to-year WSMV transmis- sion. The efficacy of planting date restrictions in Montana supports this. Following a severe epidemic of WSMV in the primary winter wheat production region of the state in 1993 and 1994 (22,23), planting date recommendations were established by the Risk Management Agency and put forth as the best management practice for Montana. There have been no major disease epidemics since these planting date recommendations were put into place.

Wheat varieties can differ in resistance and tolerance to WSMV $(7,8)$. In this study, resistance was similar among 10 winter wheat varieties commonly planted in Montana. However, some varieties were more tolerant to WSMV than others. Research is needed to determine whether tolerance differs if plants are inoculated using the vector WCM rather than mechanical inoculation, as was used in this study. Resistance was largely determined by the timing of inoculation and should be considered in evaluation of cultivars or breeding lines. For example, a late-fall inoculation may mislead researchers in the northern Great Plains to conclude that all varieties are highly resistant when theses varieties may be highly susceptible when exposed to WSMV at other times of the year.

Management of mite-transmitted cereal viruses relies on an integrated approach, informed by our understanding of the factors that drive disease risk and impacts. This study demonstrates that, in the northern Great Plains, wheat is highly resistant to WSMV infection when exposed to the virus late in the fall, suggesting that winter wheat planted in October has low risk of developing disease and associated yield losses. Implementation of late planting dates may provide greater reductions in the year-to-year spread of the WSMV epidemics in the northern Great Plains compared with the southern Great Plains and may, in part, explain why incidence of WSMV is higher in the lower latitudes of the Great Plains (M. Burrows, personal communication). However, producers adopting this management recommendation should consider the potential impact of yield loses due to late planting. In areas of high disease risk, producers should consider planting WSMV-tolerant varieties. Also, past planting recommendations should be reevaluated in the face of changing climate conditions.

\section{Acknowledgments}

This work was supported with funding from the Montana Wheat and Barley Committee and the United States Department of Agriculture Crops at Risk Program. We thank J. Berg, P. Bruckner, S. Lanning, L. Talbert, and B. Schaff for their contributions to this study.

\section{Literature Cited}

1. Bottacin, A., and Nassuth, A. 1990. Evaluation of Ontario-grown cereals for susceptibility to wheat streak mosaic virus. Can. J. Plant Pathol. 12:267272.

2. Brey, C. W., Johnson, G. D., and Blodgett, S. L. 1998. Survey of Montana grasses for wheat curl mite (Acari: Eriophyidae), the vector of Wheat streak mosaic virus. J. Agric. Entomol. 15:173-181.

3. Burrows, M., Rush, C., and Franc, G. 2009. Occurrence of viruses in wheat in the Great Plains region, 2008. Plant Health Progress. Online publication. doi:10.1094/PHP-2009-0706-01-RS

4. Carrera, S. G., Davis, H., Aguirre-Rojas, L., Murugan, M., and Smith, C. M. 2012. Multiple categories of resistance to wheat curl mite (Acari: Eriophyidae) expressed in accessions of Aegilops tauschii. J. Econ. Entomol. 105:2180-2186.

5. Carrigan, L. L., Ohm, H. W., Foster, J. E., and Patterson, F. L. 1981. Response of winter wheat cultivars to Barley yellow dwarf virus infection. Crop Sci. 21:377-380.

6. Christian, M. L., and Willis, W. G. 1993. Survival of wheat streak mosaic virus in grass hosts in Kansas from wheat harvest to fall wheat emergence. Plant Dis. 77:239-242.

7. Divis, L. A., Graybosch, R. A., Peterson, C. J., Baenziger, P. S., Hein, G. L., Beecher, B. B., and Martin, T. J. 2006. Agronomic and quality effects in winter wheat of a gene conditioning resistance to Wheat streak mosaic virus. Euphytica 152:41-49.

8. Edwards, M. C., and McMullen, M. P. 1988. Variation in tolerance to wheat streak mosaic virus among cultivars of hard red spring wheat. Plant Dis. 72:705-707.

9. Fahim, M., Mechanicos, A., Ayala-Navarrete, L., Haber, S., and Larkin, P. J. 2012. Resistance to Wheat streak mosaic virus: a survey of resources and development of molecular markers. Plant Pathol. 61:425-440.

10. Harvey, T. L., Martin, T. J., Seifers, D. L., and Sloderbeck, P. E. 1997. Change in virulence of wheat curl mite detected on TAM 107 wheat. Crop Sci. 37:624-625. 
11. Harvey, T. L., Seifers, D. L., and Martin, T. J. 1998. Effect of imidacloprid seed treatment on infestations of wheat curl mite (Acari: Eriophyidae) and the incidence of wheat streak mosaic virus. J. Agric. Entomol. 15:75-81.

12. Hunger, R. M., Sherwood, J. L., Evans, C. K., and Montana, J. R. 1992. Effects of planting date and inoculation date on severity of wheat streak mosaic in hard red winter wheat cultivars. Plant Dis. 76:1056-1060.

13. Ito, D., Miller, Z., Menalled, F., Moffet, M., and Burrows, M. 2012. Relative susceptibility among alternative hosts prevalent in the Great Plains to Wheat streak mosaic virus. Plant Dis. 96:1185-1192.

14. Jiang, W., Garrett, K. A., Peterson, D. E., Harvey, T. L., Bowden, R. L., and Fang, L. 2005. The window of risk for emigration of Wheat streak mosaic virus varies with host eradication method. Plant Dis. 89:853-858.

15. Kassanis, B. 1957. Effects of changing temperature on plant virus diseases. Adv. Virus Res. 2:221-241.

16. Langham, M., Doxtader, D. C., Haley, S. D., Kalsbeck, S., Little, R. S., and Ibrahim, A. M. 2001. Yield and growth reductions in winter wheat infected with Wheat streak mosaic virus. (Abstr.) Phytopathology 91:S52

17. Levene, H. 1960. Robust tests for equality of variances. Pages 278-292 in: Contributions to Probability and Statistics. I. Olkin, ed. Stanford University Press, Palo Alto, CA

18. Lu, H. J., Price, J., Devkota, R., Rush, C., and Rudd, J. 2011. A dominant gene for resistance to Wheat streak mosaic virus in winter wheat line CO960293-2. Crop Sci. 51:5-12.

19. Myslik, J. T., and Nassuth, A. 2001. Rapid detection of viruses, transgenes, and mRNAs in small plant leaf samples. Plant Mol. Biol. Rep. 19:329-340.

20. Navia, D., de Mendonca, R. S., Skoracka, A., Szydlo, W., Knihinicki, D., Hein, G. L., Pereira, P. R. V. D., Truol, G., and Lau, D. 2013. Wheat curl mite, Aceria tosichella, and transmitted viruses: an expanding pest complex affecting cereal crops. Exp. Appl. Acarol. 59:95-143.

21. Perry, K. L., Kolb, F. L., Sammons, B., Lawson, C., Cisar, G., and Ohm, H. 2000. Yield effects of Barley yellow dwarf virus in soft red winter wheat. Phytopathology 90:1043-1048.

22. Riesselman, J., and Carlson, G. 1994. Effect of WSMV on yield in commercially grown hard red winter wheat relative to comparable long term averages. Biol. Cult. Tests 9:129.
23. Riesselman, J., and Carlson, G. 1994. Reaction of winter wheat varieties to wheat streak mosaic virus, 1993. Biol. Cult. Tests 9:130.

24. Seifers, D. L., Martin, T. J., Harvey, T. L., and Haber, S. 2007. Temperaturesensitive Wheat streak mosaic virus resistance identified in KS03HW12 wheat. Plant Dis. 91:1029-1033.

25. Seifers, D. L., Martin, T. J., Harvey, T. L., Haber, S., and Haley, S. D. 2006 Temperature sensitivity and efficacy of Wheat streak mosaic virus resistance derived from CO960293 wheat. Plant Dis. 90:623-628.

26. Shapiro, J. M. 1955. Error estimates for certain probability limit theorems. Ann. Math. Stat. 26:617-630.

27. Sill, W. H. 1953. Some characteristics of the wheat streak-mosaic virus and disease. Trans. Kans. Acad. Sci. 56:414-424.

28. Sill, W. H., and Agusiobo, P. C. 1955. Host range studies of the wheat streak mosaic virus. Plant Dis. Rep. 39:633-642.

29. Slykhuis, J. T. 1955. Aceria tulipae Keifer (Acarina: Eriophyidae) in relation to the spread of wheat streak mosaic. Phytopathology 45:116-128.

30. Slykhuis, J. T., Andrews, J. E., and Pittman, U. J. 1957. Relation of date of seeding winter wheat in Southern Alberta to losses from Wheat streak mosaic, rot root, and rust. Can. J. Plant Sci. 37:113-127.

31. Somsen, H. W., and Sill, W. H. 1970. The wheat curl mite, Aceria tulipae Keifer, in relation to epidemiology and control of wheat streak mosaic. Kans. Agric. Exp. Stn. Res. Publ. 162

32. Thomas, J. A., and Hein, G. L. 2003. Influence of volunteer wheat plant condition on movement of the wheat curl mite, Aceria tosichella, in winter wheat. Exp. Appl. Acarol. 31:253-268.

33. Velandia, M., Rejesus, R. M., Jones, D. C., Price, J. A., Workneh, F., and Rush, C. M. 2010. Economic impact of Wheat streak mosaic virus in the Texas High Plains. Crop Prot. 29:699-703.

34. Warton, D. I., and Hui, F. K. C. 2011. The arcsine is asinine: the analysis of proportions in ecology. Ecology 92:3-10.

35. Wegulo, S. N., Hein, G. L., Klein, R. N., and French, R. C. 2008. Managing wheat streak mosaic. University of Nebraska-Lincoln Extension. EC1871. http://www.ianrpubs.unl.edu/live/ec1871/build/ec1871.pdf

36. Willis, W. G. 1984. Wheat diseases. Kans. State. Univ. Coop. Ext. Serv. Bull. S-23. 